\title{
Barriers to Accessing Nighttime Supervisors: a National Survey of Internal Medicine Residents
}

\author{
Jillian S. Catalanotti, MD, MPH' (D, Alec B. O'Connor, MD, MPH', \\ Michael Kisielewski, MA 3 , Davoren A. Chick, MD ${ }^{4,5}$, and Kathlyn E. Fletcher, MD, MA
}

'Department of Medicine, Division of General Internal Medicine, The George Washington University, 2150 Pennsylvania Avenue, NW - Suite 5-416, Washington, DC, USA; ${ }^{2}$ Department of Medicine, University of Rochester School of Medicine and Dentistry, Rochester, NY, USA; ${ }^{3} \mathrm{Alliance}$ for Academic Internal Medicine, Alexandria, VA, USA; ${ }^{4}$ Department of Medicine, University of Pennsylvania Perelman School of Medicine, Philadelphia, PA, USA; ${ }^{5}$ American College of Physicians, Philadelphia, PA, USA; ${ }^{6}$ Department of Medicine, Medical College of Wisconsin/ Milwaukee VAMC, Milwaukee, WI, USA.

BACKGROUND: Single-center studies have reported residents experience barriers to accessing supervising physicians overnight, but no national dataset has described barriers perceived by residents or the association between supervision models and perceived barriers.

OBJECTIVE: To explore residents' perception of barriers to accessing overnight supervision.

DESIGN: Questions about overnight supervision and barriers to accessing it were included on the American College of Physicians Internal Medicine In-Training Examination ${ }^{\circledR}$ (IM-ITE $\left.®\right)$ Resident Survey in Fall 2017.

PARTICIPANTS: All US-based internal medicine residents who completed the 2017 IM-ITE $\AA$. Responses from 20,744 residents (84\%) were analyzed.

MAIN MEASURES: For our main outcome, we calculated percentages of responses for eight barriers and tested for association with the presence or absence of nocturnists. For our secondary outcome, we categorized free-text responses enumerating barriers from all residents into the five Systems Engineering Initiative for Patient Safety (SEIPS) categories to elucidate future areas for study or intervention.

KEY RESULTS: Internal medicine residents working in hospitals without nocturnists more commonly reported having at least one barrier to accessing a supervising physician "always" or "most of the time" (5075/9842, $51.6 \%)$ compared to residents in hospitals with nocturnists (3074/10,902, 28.2\%, $p<0.001)$. Among residents in hospitals without nocturnists, the most frequently reported barrier to accessing attending supervision was attendings not being present in the hospital (30.4\% "always" or "most of the time"); residents in hospitals with nocturnists most frequently reported desire to make their own decisions as a barrier to contacting attendings (15.7\% "always" or "most of the time"). Free-text

Prior Presentations A subset of these findings were presented by the authors as a poster presentation at the Society for General Internal Medicine national meeting on May 9, 2019, in Washington, DC, and as a podium presentation at the Alliance for Academic Internal Medicine (AAIM) Fall Meeting on October 18, 2019, in Denver, CO.

Received June 20, 2020

Accepted December 20, 2020

Published online January 28, 2021 responses from residents with and without nocturnists most commonly revealed organization (47\%) barriers to accessing supervision; $28 \%$ cited person barriers, and $23 \%$ cited tools/technology barriers.

CONCLUSIONS: Presence of nocturnists is associated with fewer reported barriers to contacting supervising physicians overnight. Organizational culture, work schedules, desire for independence, interpersonal interactions, and technology may present important barriers.

KEY WORDS: graduate medical education; supervision; nocturnist; hospitalist.

J Gen Intern Med 36(7):1974-9

DOI: $10.1007 / \mathrm{s} 11606-020-06516-4$

(C) Society of General Internal Medicine 2021

\section{INTRODUCTION}

The essence of internal medicine (IM) residency is experiential learning that occurs through managing patients with increasing responsibility while appropriately supervised. ${ }^{1-3}$ Data assessing the relationship between resident supervision and patient safety outcomes are mixed, ${ }^{2,}{ }^{4}$ but IM residents and attending physicians perceive that increased supervision improves quality of care. ${ }^{2,5-8}$ Residents must practice with supervision that ensures patient safety while identifying gaps in resident knowledge or skills to be addressed prior to practicing independently. ${ }^{9}$ Put another way, residents must be able to develop their autonomy while delivering safe, high quality patient care.

Nighttime rotations historically have been opportunities for residents to exercise greater autonomy because supervision often occurs indirectly, with the supervisor not physically in the hospital. ${ }^{10}$ Residents' increased nighttime independence typically has arisen by default rather than by deliberate, individualized assessment of the amount of supervision needed. Notably, the 2009 Institute of Medicine report on duty hours and supervision recommended "that programs provide adequate, direct, onsite supervision for residents."11 Over a decade later, despite the increasing volume and complexity of overnight admissions to hospitals, ${ }^{12,13}$ and that residents have 
reported a variety of barriers to accessing at-home supervising physicians overnight, ${ }^{5}$ many residents are supervised at night by at-home attendings. ${ }^{8}$ Other teaching hospitals have hired in-house overnight hospitalists ("nocturnists") to expand patient care capacity and increase overnight supervision of residents, ${ }^{5-7,10}$ but the effect of nocturnists on residents and patients has not been well studied.

We previously used a national survey of IM residents to report a positive association between the presence of a nocturnist and resident perception of having sufficient overnight supervision to ensure patient safety. ${ }^{8}$ The primary objective of the current study was to analyze other responses from the same dataset regarding resident perceptions of barriers to accessing supervising physicians overnight, with assessment of whether barriers varied between residents working in hospitals with nocturnists compared to those without nocturnists. The secondary objective was to categorize free-text responses describing barriers to accessing overnight supervision to elucidate areas for further study or action.

\section{METHODS}

The American College of Physicians Internal Medicine InTraining Examination $®$ (IM-ITE $®)$ is a national examination administered annually in August and September to internal medicine residents worldwide. The IM-ITE® is widely used in the USA; over $95 \%$ of US IM residents take the examination. ${ }^{14}$ It is optional and programs pay for enrollment. Each year, a confidential resident survey is administered at the end of the exam to all test takers. We authored questions about overnight supervision for inclusion on the 2017 IM-ITE® Resident Survey (Appendix).

\section{Subjects}

Of the 24,620 post-graduate year (PGY) 1, 2, or 3 residents in US IM residencies who sat for the 2017 IM-ITE®, 23,553 residents completed the survey. Among respondents, $2809 \mathrm{did}$ not allow their responses to be analyzed for scholarly publication. We analyzed data from the remaining 20,744 respondents $(84 \%)$.

\section{Data Collected}

The presence of a nocturnist was determined by a "yes" or "no" response to the question: "Does your internal medicine residency program have an attending physician who stays in the hospital overnight and is responsible for directly supervising internal medicine residents providing care on medicine wards?" Residents were also asked "How often does each of the following act as a barrier to your contacting an attending level physician to supervise you at night?" with eight potential barriers listed, using a 5-point Likert scale with response options of "always," "most of the time," "sometimes," "rarely," and "never." The eight potential barriers were selected using similar survey questions asked of IM residency program directors by the Association of Program Directors in Internal Medicine in 2009 and 2017. ${ }^{15}$ Participants were then asked a free-text response question: "What else, if anything, acts as a barrier to your contacting an attending level physician to supervise you at night?"

\section{Statistical Analysis}

We used descriptive statistics (frequencies and percentages) to report the responses to closed-ended questions overall and stratified by the presence or absence of nocturnists. To simplify the representation of the data and to summarize the barriers that residents felt were most common, our primary analysis combined the responses of "always" and "most of the time" to how often each of the eight items was perceived as barriers. We dichotomized those response options because we postulated that "always" and "most of the time" represented the most persistently problematic barriers that might justify attention by program directors and hospital leaders. In sensitivity analyses, we verified that reported associations were not dependent on our dichotomization threshold using the adjusted Wald (Pearson) chi-square test (1 degree of freedom) to test for differences on each scale point between the presence or absence of a nocturnist for each barrier. We used Cronbach's alpha $(\alpha)$ to confirm the internal consistency of the eight items and how well they represented possible barriers ( $\alpha=0.8299$ [test scale]; average interitem correlation $=$ 0.3870 ; scale reliability coefficient $=0.8347$ ); an interitem correlation between 0.20 and 0.40 was deemed acceptable. $^{16}$ To ensure that the results were not confounded by post-graduate year, we used Kendall's tau-b $\left(\tau_{\mathrm{b}}\right)$ correlation coefficient, interacting post-graduate year with each of the response options to "How often does each of the following act as a barrier to your contacting an attending level physician to supervise you at night?" ( $p<0.001$ for all eight items; Table 1). Finally, we used the Wald chi-square statistic to test for an association between the presence or absence of nocturnists and reporting at least one item as a barrier "always" or "most of the time," versus not reporting any barrier "always" or "most of the time." Data analysis was performed in Stata SE 16.1 (StataCorp. 2019. Stata Statistical Software: Release 16. College Station, TX: StataCorp LLC.)

We performed content analysis ${ }^{17}$ of free-text responses to "other" perceived barriers to calling attendings at night. We categorized the responses based on the Systems Engineering Initiative for Patient Safety (SEIPS) model ${ }^{18}$ (see Table 2), which identifies contributors to patient safety problems related to five factors: tasks (being too busy to call or perceiving attendings as too busy to help), tools/technology (not being aware of whom to call or not receiving a response to an attempted contact), person (desire for autonomy; familiarity, personality, or perceived utility of contacting attendings), 
Table 1 Reported Frequency of Each Item Being a Barrier to Contacting an Attending Physician Overnight. Responses to the Question, "How Often Does Each of the Following Act as a Barrier to Your Contacting an Attending Level Physician to Supervise You at Night?" from Most to Least Frequent as Determined by the Sum of "Always" and "Most of the Time" Percentages $(n=20,744)$

\begin{tabular}{|c|c|c|c|c|c|}
\hline Potential barriers & Always & $\begin{array}{l}\text { Most of the } \\
\text { time }\end{array}$ & Sometimes & Rarely & Never \\
\hline Want to make decisions on my own & $756(3.6 \%)$ & $3264(15.7 \%)$ & $\begin{array}{l}7194 \\
(34.7 \%)\end{array}$ & $\begin{array}{l}3787 \\
(18.3 \%)\end{array}$ & $\begin{array}{l}5743 \\
(27.7 \%)\end{array}$ \\
\hline Do not want to wake up attending physician & $940(4.5 \%)$ & $2942(14.2 \%)$ & $\begin{array}{l}6107 \\
(29.4 \%)\end{array}$ & $\begin{array}{l}3998 \\
(19.3 \%)\end{array}$ & $\begin{array}{l}6757 \\
(32.6 \%)\end{array}$ \\
\hline Attending physician not physically in hospital & $\begin{array}{l}1366 \\
(6.6 \%)\end{array}$ & $2296(11.1 \%)$ & $\begin{array}{l}5158 \\
(24.9 \%)\end{array}$ & $\begin{array}{l}3823 \\
(18.4 \%)\end{array}$ & $\begin{array}{l}8101 \\
(39.1 \%)\end{array}$ \\
\hline $\begin{array}{l}\text { Attending physicians(s) do not specify parameters for contacting } \\
\text { them }\end{array}$ & $776(3.7 \%)$ & $2115(10.2 \%)$ & $\begin{array}{l}5756 \\
(27.8 \%)\end{array}$ & $\begin{array}{l}4017 \\
(19.4 \%)\end{array}$ & $\begin{array}{l}8080 \\
(39.0 \%)\end{array}$ \\
\hline $\begin{array}{l}\text { Afraid attending physician will perceive me as lacking } \\
\text { knowledge }\end{array}$ & $599(2.9 \%)$ & $1699(8.2 \%)$ & $\begin{array}{l}5562 \\
(26.8 \%)\end{array}$ & $\begin{array}{l}4820 \\
(23.2 \%)\end{array}$ & $\begin{array}{l}8064 \\
(38.9 \%)\end{array}$ \\
\hline $\begin{array}{l}\text { Afraid attending physician will perceive me as lacking } \\
\text { confidence }\end{array}$ & $569(2.7 \%)$ & $1570(7.6 \%)$ & $\begin{array}{l}5455 \\
(26.3 \%)\end{array}$ & $\begin{array}{l}4937 \\
(23.8 \%)\end{array}$ & $\begin{array}{l}8213 \\
(39.6 \%)\end{array}$ \\
\hline I do not need the input of the attending physician & $276(1.3 \%)$ & $1723(8.3 \%)$ & $\begin{array}{l}5527 \\
(26.6 \%)\end{array}$ & $\begin{array}{l}4750 \\
(22.9 \%)\end{array}$ & $\begin{array}{l}8468 \\
(40.8 \%)\end{array}$ \\
\hline Attending physicians do not want to be interrupted at home & $477(2.3 \%)$ & $1301(6.3 \%)$ & $\begin{array}{l}4311 \\
(20.8 \%)\end{array}$ & $\begin{array}{l}4700 \\
(22.7 \%)\end{array}$ & $\begin{array}{l}9955 \\
(48.0 \%)\end{array}$ \\
\hline
\end{tabular}

Cronbach's alpha: 0.8299 (test scale); average interitem correlation $=0.3870$; scale reliability coefficient $=0.8347$

Kendall's tau-b $\left(\tau_{b}\right)$ correlation coefficient, interacting post-graduate year with each of the response options above; $\alpha=0.01 ; p<0.001$ for all eight items; $\tau_{b}$ (range) for all eight tests: -0.1275 to 0.0268

organization (culture, work schedules), and physical environment (proximity of work areas). Two reviewers (JC and KF) scored the items independently and disagreements in scoring were discussed until consensus was reached. Responses were categorized by as many SEIPS factors as they contained or were deemed not codable if they did not describe barriers to contacting attendings. We did not stratify free-text responses by presence or absence of nocturnists because they were not meant to be as scientifically precise as our quantitative data; the objective was to collect them only to describe future areas for study or action.

This study was declared exempt by The George Washington University Committee on Human Research Institutional Review Board (IRB), \#180471.

\section{RESULTS}

Thirty-four percent of the 20,744 survey respondents were PGY1s, 35\% PGY2s, and 31\% PGY3s. Our dataset was statistically representative of all IM residents training in the USA: $93 \%$ were categorical IM or primary care residents, $57 \%$ were male (compared to $58 \%$ nationally), and $62 \%$ were graduates of US medical schools (compared to $49.4 \%$ nationally). ${ }^{14}$ Demographics for this population were presented previously, as was the percentage (53\%) who reported having a nocturnist. $^{8}$

Overall, $39.3 \%$ of respondents $(8149 / 20,744)$ reported at least one of the eight items to be barriers "always" or "most of the time." Among residents who reported having a nocturnist present, $28.2 \%$ reported at least one item to be a barrier, compared to $51.6 \%$ of residents who reported not having a nocturnist $(p<0.001)$.

The three most commonly reported barriers to contacting attendings at night, from most to least frequent, were
(1) wanting to make their own decisions, (2) not wanting to wake up the attending, and (3) the attending not being located in the hospital (Table 1). Among residents without a nocturnist, the most commonly selected barrier was the attending not being in the hospital, followed by not wanting to wake up the attending, and wanting to make their own decisions (Fig. 1). Among residents working with a nocturnist, the most commonly selected barrier was wanting to make their own decisions, followed by not wanting to wake up the attending, and the attending not specifying parameters to contact them. Every barrier to contacting a supervising physician was selected less frequently when a nocturnist was present (Fig. 1). Appendix Table 3 completely describes the non-dichotomized responses to each item. A higher percentage of residents without a nocturnist generally reported "always" or "most of the time" with respect to each barrier, with this pattern reversing as the scale moved toward "sometimes," "rarely," and "never."

Of the 2429 free-text responses to the question, "What else, if anything, acts as a barrier to your contacting an attending level physician to supervise you at night?," 367 were codable (15\%) and 2062 were not. Non-codable responses included those that were uninterpretable (e.g., "don't know," "try"), non-answers (e.g., "NA," "None," "Everything listed," "I don't know because I haven't done nights yet," "Really? A survey?"), or described positive experiences related to supervision (e.g., "it helps that we have a 'must call-list' posted in our overnight on call/work rooms"). The 367 codable free-text responses listing barriers to contacting an overnight supervising attending fell into all five SEIPS categories (Table 2). The two reviewers demonstrated $79 \%$ initial agreement on assigned SEIPS categories for at least one factor in each response, and discussion led to $100 \%$ consensus. Organization factors comprised $47 \%$ of responses followed by person factors $(28 \%)$ and technology factors $(23 \%)$. 
Table 2 Summary of Free-Text Responses to the Question, "What Else, if Anything, Acts as a Barrier to Your Contacting an Attending Level Physician to Supervise You at Night?" by SEIPS ${ }^{18}$ Category with Definitions, Examples, and Frequencies

\begin{tabular}{|c|c|c|c|}
\hline & Definition & Specific verbatim examples & $\begin{array}{l}n(\%) \dagger \text { of } \\
\text { comments }\end{array}$ \\
\hline Organization $*$ & $\begin{array}{l}\text { Work schedules, culture of the organization, explicit } \\
\text { policies and choices, supervisory style, hidden } \\
\text { curriculum, communication, and teamwork factors }\end{array}$ & $\begin{array}{l}\text { - "advised not to per residency policy" } \\
\text { - "there is no parameter or protocol to justify when to } \\
\text { call attending" } \\
\text { " "they might eat me alive the next day" } \\
\text { "peer factors- when other residents typically don't call } \\
\text { the attendings, it takes courage and dedication to } \\
\text { getting it right for the patient. i will always do this, but } \\
\text { i can see how residents may be afraid of how it reflects } \\
\text { on them in the next stage of fellowships/jobs" }\end{array}$ & $174(47 \%)$ \\
\hline Person* & $\begin{array}{l}\text { Individual characteristics of the reporting resident such } \\
\text { as confidence, knowledge, or motivation; } \\
\text { characteristics of others such as attendings }\end{array}$ & $\begin{array}{l}\text { - "mostly don't want to bother people if potentially } \\
\text { unnecessary" } \\
\text { " "some of the physicians who take call at the hospital } \\
\text { are relatively unknown to the non-senior residents in } \\
\text { the hospital---they are only physically met and inter- } \\
\text { acted with in person during out-rotations in the } 2 \text { nd or } \\
\text { 3rd year.as such, residents cannot accurately gauge the } \\
\text { attitudes and desires of these 'guest' attendings.of } \\
\text { course, serious and necessary calls will still be made, } \\
\text { but i feel that this presents somewhat of a barrier with } \\
\text { unfamiliarity and lack of comfort between this } \\
\text { sub-population of attendings and less senior residents" }\end{array}$ & $102(28 \%)$ \\
\hline $\begin{array}{l}\text { Tools/ } \\
\text { technology* }\end{array}$ & $\begin{array}{l}\text { Technology/tools used to access supervision within the } \\
\text { healthcare setting such as the electronic health record, } \\
\text { paging systems, and accessing call schedules }\end{array}$ & $\begin{array}{l}\text { " "information on communication structures in the } \\
\text { hospital. the directories are not widely / publicly } \\
\text { available" } \\
\text { " "unclear who to contact" } \\
\text { " "they do not wake up or respond to my attempts to } \\
\text { contact them when i attempt to contact them" }\end{array}$ & $84(23 \%)$ \\
\hline Tasks* & $\begin{array}{l}\text { Workload, time pressure, cognitive load, and other } \\
\text { demands of the job; actual content of the work to be } \\
\text { done, and level of expected job autonomy }\end{array}$ & $\begin{array}{l}\text { " "too busy to have the time to let the attending know" } \\
\text { "they are too busy and covering too many other } \\
\text { patients at night" }\end{array}$ & $65(18 \%)$ \\
\hline $\begin{array}{l}\text { Physical } \\
\text { environment* }\end{array}$ & $\begin{array}{l}\text { Physical environmental layout of the hospital and work } \\
\text { stations }\end{array}$ & $\begin{array}{l}\text { "physical separation even in the rare event that one is } \\
\text { in-house (e.g. the night triage hospitalist in theory acts } \\
\text { as an available attending, but in practice I would not } \\
\text { know how to find this person)" }\end{array}$ & $5(1 \%)$ \\
\hline
\end{tabular}

* Based on the factors defined in the SEIPS model

†Denominator $=367$ codable responses (some responses had more than one code assigned)

\section{DISCUSSION}

We surveyed the majority of IM residents in the USA and found residents without nocturnists reported having at least one barrier to contacting a supervising attending overnight nearly twice as often as those with nocturnists did. We found many similar barriers to accessing overnight supervising attendings regardless of whether or not the resident reported having a nocturnist; however, there were important differences in barriers reported between these two groups. Among residents with nocturnists, the most common barrier related to residents' expectations for themselves: residents did not access supervision because they wanted to make their own decisions. In contrast, among residents without nocturnists, the most frequently reported barrier to accessing supervision was reluctance to call attendings not located in the hospital. Both groups expressed hesitancy to wake a supervising attending overnight.

In previous work, we demonstrated that a higher percentage of residents who reported having a nocturnist reported "always" receiving adequate supervision to ensure patient safety overnight, compared to those who did not have a nocturnist $(61.3 \%$ vs $40.5 \%$, respectively; $p<0.001){ }^{8}$ The current study offers some explanations. All of the barriers to accessing overnight supervising physicians about which residents were queried were less frequently reported by residents with a nocturnist. Some of these barriers would be expected to be mitigated by having a nocturnist (e.g., not wanting to wake an attending), whereas the presence of nocturnists mitigating other barriers was surprising (e.g., residents wanting to make decisions on their own or being afraid the attending will perceive them as lacking knowledge).

It is possible that increasing attending supervision overnight may have an even greater effect than during the day due to fewer providers being in the hospital who could serve as sources of real-time advice, supervision, or error correction. This may be exacerbated by the potentially longer time gap overnight between resident decisions and attending assessment of the patient to potentially correct suboptimal resident actions, particularly in the absence of a nocturnist. Previous work suggests that when given sample clinical scenarios, attending physicians expect real-time supervisory communication more often than residents do. ${ }^{19,}{ }^{20}$ Although some reluctance by residents to call their supervisor is useful educationally, it can compromise patient safety. ${ }^{21}$ Our results suggest that the presence of a nocturnist might mitigate residents' reluctance to seek help overnight. 


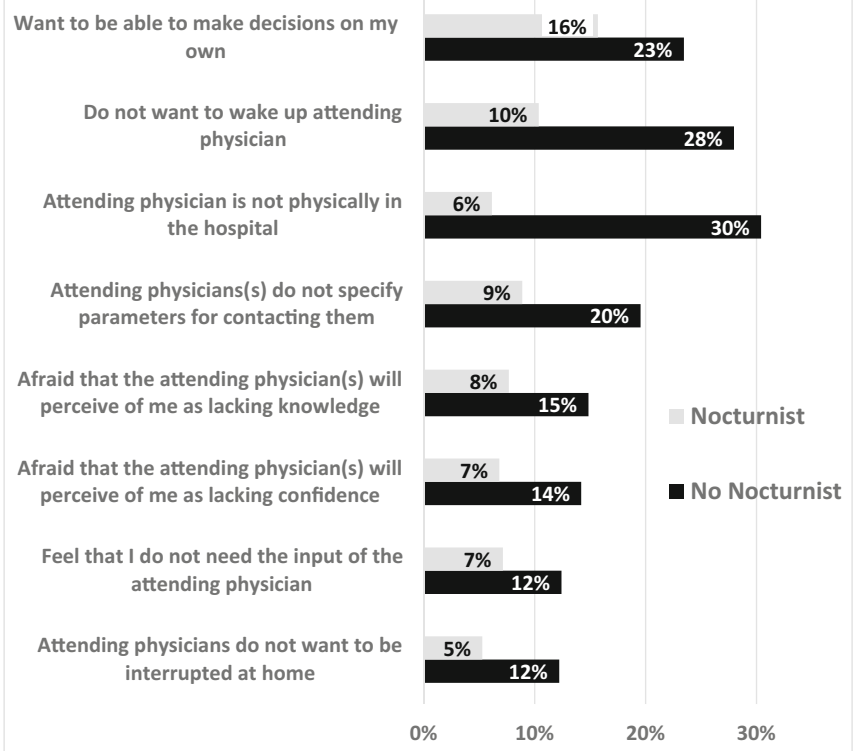

Figure 1 Percentage of residents by nocturnist status reporting that a barrier is present "always" or "most of the time." Responses to the question, "How often does each of the following act as a barrier to your contacting an attending level physician to supervise you at night?" stratified by whether or not respondents reported having a nocturnist attending. Percentages given are for residents indicating that the answer was a barrier "Always" or "Most of the Time." $p<0.001$ for all comparisons.

Free-text responses generated additional barriers to contacting attendings, which might warrant local attention or further study. These barriers fell into all five SEIPS categories. Surprisingly, some residents reported technology barriers to contacting attendings, including not having access to a call schedule or phone numbers, and attending physicians not returning pages or phone calls. Since these technology barriers are rectifiable, we recommend that program directors ask residents whether they have encountered these problems overnight and take corrective action on identified simple technology barriers.

Residents' free-text responses also revealed that nocturnists' roles and types of interactions with residents varied (e.g., predominantly performing their own overnight work vs supervising residents: "they are busy doing admissions of their own," "there are different ones at night so you have to get used to each different person's expectations and style and not all of them are as completely trustworthy to us in terms of practicing evidence based medicine"), which may explain some of the variation in supervision experienced by residents with nocturnists. This finding is not surprising since not all nocturnists are expected to have supervisory responsibilities for residents. ${ }^{5,10}$ Residents noted the workloads of both residents and nocturnists (task factors) as barriers to supervision, which suggests that correcting inadequacy of overnight staffing may be another critical factor in optimizing resident supervision.

Selecting appropriate physicians to serve as nocturnists may be just as important as defining responsibilities of the role (person factors). Often, nocturnists are early-career physicians or recent graduates of a local training program. Free-text responses support this practice, citing increased comfort approaching attendings with whom they were already familiar, or whom they believed could relate to their present experience. Supervisory style (organization factor) is also important; responses align with prior reports that residents may feel hesitant to reach out to attendings who have not established clear parameters for contact. ${ }^{19}$ Some respondents also noted the importance of physical proximity (environment factor) in the hospital between residents and the nocturnists as a factor that would increase their likelihood of reaching out for supervision.

The strengths of this study include its size and high, representative response rate. Limitations include its cross-sectional survey design, which allows for assessment of statistical association but not causation. Additionally, since the survey was administered at the end of a lengthy examination day, it is possible that respondents were fatigued or not fully engaged; however, participation was voluntary and patterns in the responses, including free-text responses, suggest active survey participation. Finally, our survey measured resident perceptions rather than objective outcome measures.

The balance between developing independence and adequate supervision is important to residency training; nighttime clinical rotations present special challenges in achieving this balance. In our study, the presence of a nocturnist was significantly associated with residents reporting fewer barriers to accessing a supervising physician.

Across all residents, barriers to contacting a supervising physician to seek guidance overnight, as elicited through free-text responses, revealed the important impact of organizational culture and work schedules, as well as historical or 
feared interpersonal interactions, irrespective of the presence of a nocturnist. Technological barriers were reported rather frequently and should be identified for improvement. Future work should address concrete barriers, such as staffing models, explicitly setting expectations for contact, and responsibilities of nocturnists that may compete with their supervisory roles.

Supplementary Information The online version contains supplementary material available at https://doi.org/10.1007/ s11606-020-06516-4.

Acknowledgments: The authors would like to thank the American College of Physicians for including our survey questions on the 2017 IM-ITE ${ }^{\circledR}$ Resident Survey and sharing the data with us for analysis. We would also like to thank the Alliance for Academic Medicine (AAIM) Executive Committee for its blinded review of the survey questions and the AAIM - Association of Program Directors in Internal Medicine Survey and Scholarship Committee for its support in editing the survey questions.

Corresponding Author: Jillian S. Catalanotti, MD, MPH; Department of Medicine, Division of General Internal Medicine, The George Washington University, 2150 Pennsylvania Avenue, NW - Suite 5416, Washington, DC 20037, USA (e-mail: Jcatalanotti@mfa.gwu. edu).

\section{Compliance with Ethical Standards:}

Conflict of Interest: The authors declare that they do not have a conflict of interest.

\section{REFERENCES}

1. ACGME Program Requirements for Graduate Medical Education in Internal Medicine. Available at https://www.acgme.org/Portals/0/PFAssets/ProgramRequirements / 140_InternalMedicine_2019.pdf?ver=201906-25-100749-597 Accessed 07/22/2019.

2. Finn KM, Metlay JP, Chang $\mathbf{Y}$, et al. Effect of Increased Inpatient Attending Physician Supervision on Medical Errors, Patient Safety, and Resident Education: A Randomized Clinical Trial. JAMA Intern Med 2018; 178:952-9.

3. Kennedy $\mathbf{T} \mathbf{J}$. Towards a tighter link between supervision and trainee ability. Med Educ 2009;43:1126-8.

4. Blum AB, Shea S, Czeisler CA, Landrigan CP, Leape L. Implementing the 2009 Institute of Medicine recommendations on resident physician work hours, supervision, and safety. Nat Sci Sleep 2011;3:47-85.

5. Haber LA, Lau CY, Sharpe BA, et al. Effects of increased overnight supervision on resident education, decision-making, and autonomy. J Hosp Med 2012;7;606-10.

6. Bricker DA, Markert RJ. Night float teaching and learning: perceptions of residents and faculty. J Grad Med Educ 2010;2: 236-41.

7. Trowbridge RL, Almeder L, Jacquet $\mathbf{M}$, Fairfield $\mathbf{K M}$. The effect of overnight in-house attending coverage on perceptions of care and education on a general medical service. J Grad Med Educ 2010;2:53-6.

8. Catalanotti JS, O'Connor AB, Kisielewski M, Chick DA, Fletcher KE Association Between Nocturnist Supervision and Perceived Overnight Supervision Adequacy Among Internal Medicine Residents in the US. JAMA. 2020;323(14): 1407-1409.

9. ACGME Common Program Requirements (Residency). Available at https://www.acgme.org/Portals/0/PFAssets/ProgramRequirements/ CPRResidency2019.pdf Accessed 07/22/2019.

10. Farnan JM, Burger A, Boonyasai RT, et al. Survey of overnight academic hospitalist supervision of trainees. J Hosp Med 2012;7:521-3.

11. Institute of Medicine 2009. Resident Duty Hours: Enhancing Sleep, Supervision, and Safety. Washington, DC: The National Academies Press. $10.17226 / 12508$.

12. Hundert SA, White AA, Reilly DF. Number of general medicine hospital admissions performed by internal medicine residents before and after the 2011 duty-hour regulations. South Med J 2015;108:476-81.

13. Clark AV, LoPresti CM, Smith TI. Trends in Inpatient Comorbidity and Electronic Health Data: Implications for Resident Workload Intensity. J Hosp Med 2018;13:570-2.

14. Brotherton SE, Etzel SI. Graduate Medical Education, 2017-2018. JAMA. 2018;320(10):1051-1070.

15. Alliance for Academic Internal Medicine. Association of Program Directors in Internal Medicine Annual Survey of Residency Program Directors Study Database: 2009-2017. Alexandria, VA: 22314.

16. Heo, Moonseong \& Kim, Namhee \& Faith, Myles. (2015). Statistical power as a function of Cronbach alpha of instrument questionnaire items. BMC Medical Research Methodology. 15. https://doi.org/10. 1186/s12874-015-0070-6

17. Elo S, Kyngäs $\mathbf{H}$. The qualitative content analysis process. J Adv Nurs. 2008;62(1):107-115.

18. Carayon P, Schoofs Hundt A, B-T Karsh B-T, et al. Work system design for patient safety: the SEIPS model. Qual Saf Health Care. 2006; 15(Suppl 1): i50-i58.

19. Loo L, Puri N, Kim DI, et al. "Page me if you need me": The hidden curriculum of attending-resident communication. J Grad Med Educ 2012;4:340-5

20. Palakshappa D, Carter LP, El Saleeby CM. Discrepancies in After-Hours communication attitudes between pediatric residents and supervising physicians. J Pediatr 2015; 167:1429-35.

21. Kennedy TJT, Regehr G, Baker GR, Linegard LA. 'It's a cultura expectation....' The pressure on medical trainees to work independently in clinical practice. Med Educ 2009;43:645-53.Publisher's note Springer Nature remains neutral with regard to jurisdictional claims in published maps and institutional affiliations.

Publisher's Note: Springer Nature remains neutral with regard to jurisdictional claims in published maps and institutional affiliations. 